\title{
REGIONAL AND TELESEISMIC EVENT DETECTION CAPABILITY OF THE SMALL- APERTURE TRIPOLI SEISMIC ARRAY, GREECE
}

\author{
Pirli M. ${ }^{1}$, and Schweitzer J. ${ }^{2}$ \\ ${ }^{1}$ National and Kapodistrian University of Athens, Faculty of Geology and Geoenvironment, \\ Department of Geophysics-Geothermics, pirli@geol.uoa.gr \\ ${ }^{2}$ NORSAR, P.O.Box 53 NO-2027,Kjeller, johannes.schweitzer@norsar.no
}

\begin{abstract}
The Tripoli Seismic Array (TRISAR) is a small-aperture array designed to monitor and locate the seismicity in the area of Greece. In this study, its detection capabilities are discussed for regional and teleseismic events. A reference event list is compiled, consisting of events of $m b \geq 5.0$ for regional and teleseismic distances $\left(A \geq 6^{\circ}\right)$, according to the ISC On-line Bulletin. TRISAR automatically detected approximately $25 \%$ of these events over the entire investigated distance range. Although TRISAR slowness vector residuals are rather large, as expected for an array of such small aperture, the benefits resulting from the use of such a system for reporting regional and teleseismic activity is obvious.
\end{abstract}

Key words: automatic algorithm, slowness vector, detectability, global seismicity.

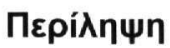

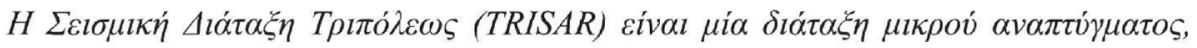

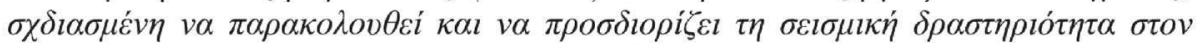

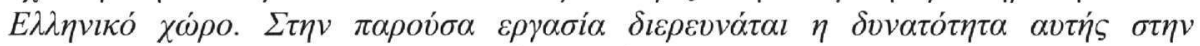

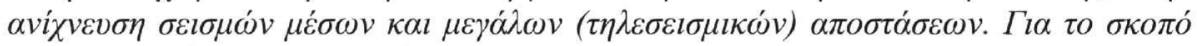

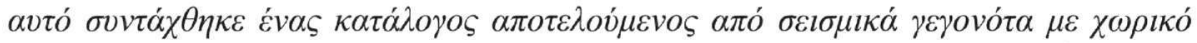

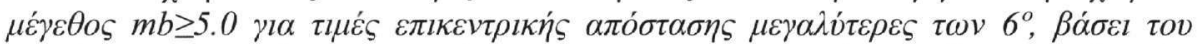

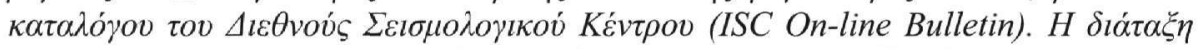

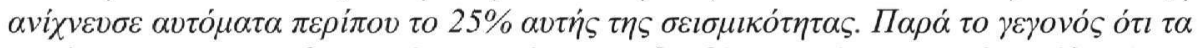

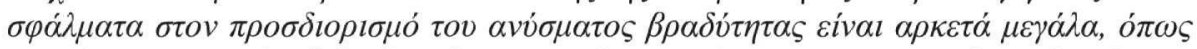

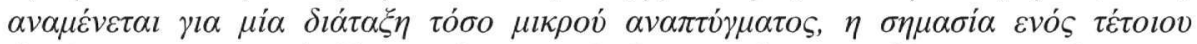

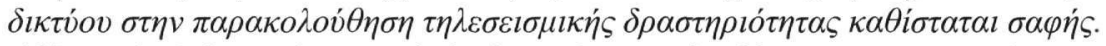

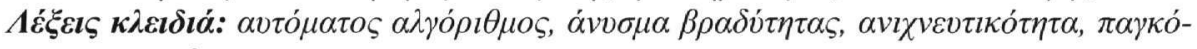

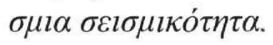

\section{Introduction}

The Tripoli Seismic Array (TRISAR) is a small-aperture array, installed and operated by the Seismological Laboratory of the University of Athens, in the vicinity of the town of Tripoli, in central Peloponnese, Greece (Pirli et al., 2004). The array consists of four 3-component elements, three of which are equipped with short period sensors $(\mathrm{CMG}-40 \mathrm{~T}-1 \mathrm{~Hz})$ and are situated at the 
peaks of an almost equilateral triangle with a maximum side length of approximately $250 \mathrm{~m}$. The fourth element, situated inside this deployment, carries a broadband sensor (CMG-40T-60s) and is appointed as reference site of the array (Fig. 1). Timing is controlled by a GPS unit for each array element, synchronising every $30 \mathrm{~min}$ and thus providing the necessary accuracy for delay-time determination. Fully automatic data acquisition is not supported, TRISAR data consisting of 30 minute long traces recorded continuously on a hard-disk, with a sample rate of 125 samples per second. Broadband records need to be converted to short-period data prior to any further analysis.

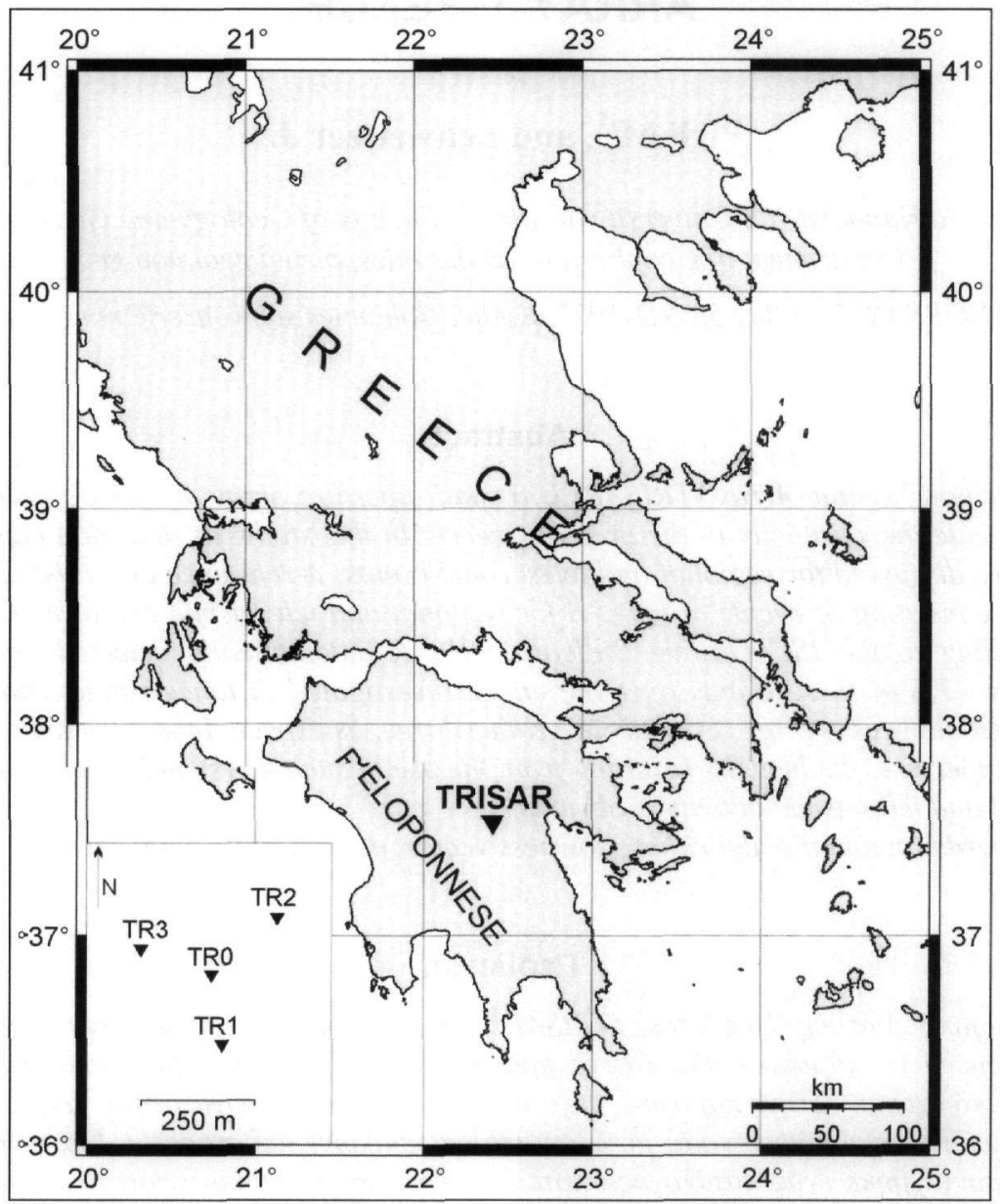

Figure 1 - Location and configuration of the Tripoli Seismic Array (TRISAR)

TRISAR operation commenced on July 16, 2003 and since then a vast amount of data has been recorded. The obtained dataset contains mostly earthquakes from the broader area of Greece, as well as records of global seismicity. Currently, the data undergo automatic analysis, using the DP (Detection Processor), EP (Event Processor) and RONAPP (Regional On-Line Array Processing Package) algorithms developed at NORSAR (Fyen 1987, 1989, Mykkeltveit and Bungum 1984, Schweitzer et al. 2002). The results are reviewed by an analyst. The automatic procedure consists of three main parts: (i) automatic detection of seismic phases, applying an STA/LTA detector on pre-defined beams, (ii) slowness vector estimation for each detected phase, using broadband f-k analysis (Kværna and Doornbos 1986, Kværna and Ringdal 1986), and (iii) grouping of individual phases into events and then locating them.

The array installation site was decided after taking into consideration the smooth topography and uniform geology in the area (Alexopoulos 1988), as well as the fact that the geographic location of 
the area of Tripoli provides the possibility to monitor a variety of high seismicity regions. There are several sources of background noise in the area, most of them due to human activities, such as the military unit where the array is installed, the nearby town of Tripoli and its surroundings, as well as the highway crossing central Peloponnese, which is located at a minimum distance of approximately $1 \mathrm{~km}$ from the array (Pirli et al. 2004, Pirli 2005). TRISAR very small aperture and restricted number of sensors limits its performance to a rather small epicentral distance range. Indeed, optimum performance in terms of slowness vector estimation accuracy is observed for the distance range between 40 and $200 \mathrm{~km}$ (Pirli 2005, Pirlis 2006). Owing to the experimental character of the array, and the fact that interest regarding its capabilities was focused on seismicity of Greece, this was not deemed as a severe disadvantage, and no investigation of TRISAR performance for regional and teleseismic seismicity was until now attempted. However, it can be expected that TRISAR will not behave much different from a typical single station on the Peloponnese since the increase of the signal-to-noise ratio due to beamforming (e.g. Schweitzer et al. 2002) is for a four element array quite limited.

In this study, we are addressing the issue of assessing TRISAR capabilities in terms of detecting seismic events within the regional and teleseismic distance range $\left(\Delta \geq 6^{\circ}\right)$. Results presented here can only be characterised as preliminary, since the time period of which TRISAR data could be analyzed is rather short: altogether, automatic data analysis results are available for only 276 days, within the time interval from July 2003 to January 2005. The uneven distribution of data availability within this time period is depicted in Figure 2.

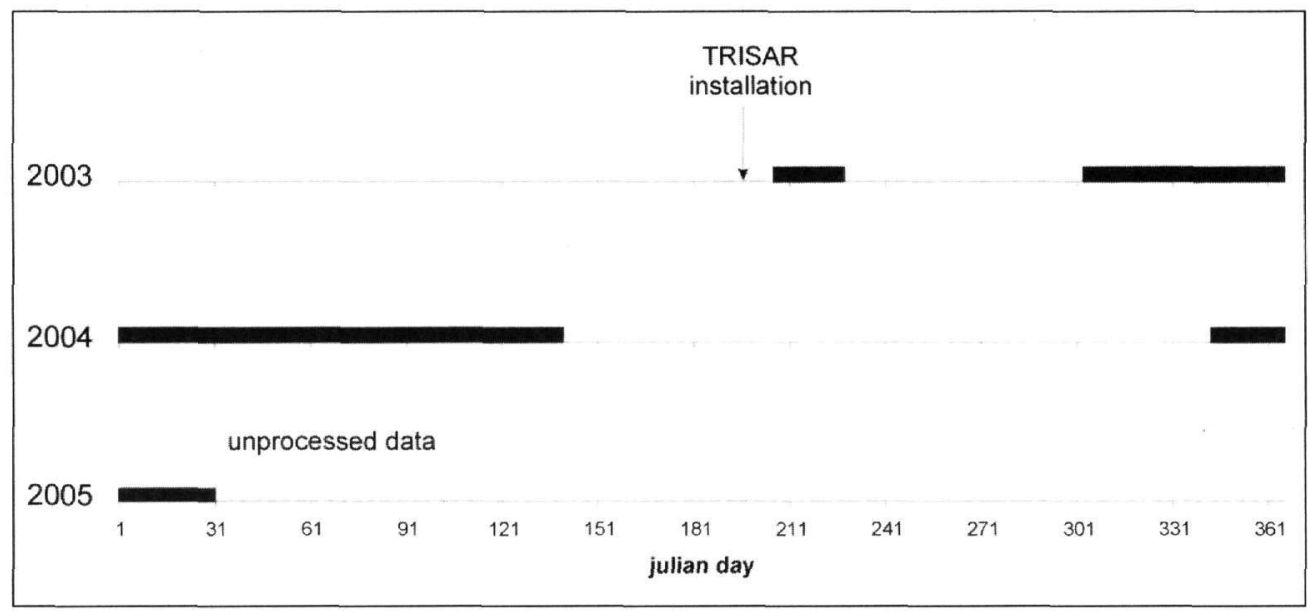

Figure 2 - Data availability for TRISAR. Shaded sections correspond to time intervals when data were used for the present study

\section{Methodology}

The automatic NORSAR algorithms, as installed at the University of Athens (Pirli, 2005), are tuned to detect and locate local and regional seismic events. In addition, they also detect and analyse far regional and teleseismic onsets. Although locating such events is not automatically possible, due to the limited array performance achieved by TRISAR (Pirli 2005, Pirlis 2006), apparent velocity and backazimuth of all detected phases are measured and flagged in the automatic system output lists, either as presumable P- or PKP-type onsets.

The following simple method was used to investigate in more detail the teleseismic capabilities of the Tripoli array. As a first step, a list of all seismic events with a body wave magnitude (mb) larger or equal to 5.0 and epicentral distances larger than $6^{\circ}$ was retrieved from the event database of the International Seismological Centre (ISC 2006). According to these criteria, 1089 seismic events were found for the time period in which automatically analysed array results are available, 
and declared as possibly observable (Fig. 3 - open circles). All source information obtained regarding events prior to August 2004 is reviewed by ISC, therefore only ISC epicentre and body wave magnitude results were requested. For the remaining time interval, (December $2004-$ January 2005), the reference list is a preliminary compilation by the ISC, mostly consisting of NEIC reported results, plus a small percentage of events reported by other sources.

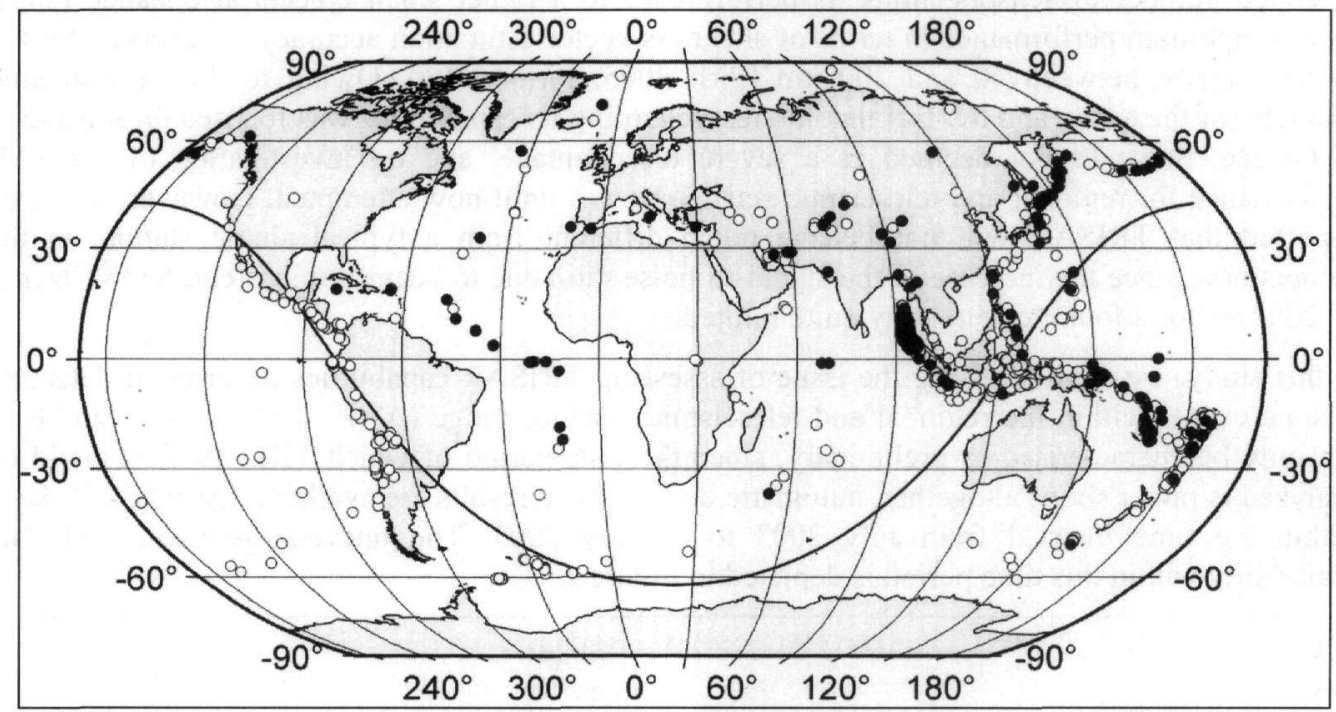

Figure 3 - Geographic distribution of the reference events used in this study $\left(\Delta \geq 6^{\circ}\right.$ and $\mathrm{mb} \geq 5.0$ ), according to the ISC On-line Bulletin (open circles). Reference events observed by TRISAR are noted with filled circles. The thick black curve denotes the $100^{\circ}$ distance range from TRISAR

In a second step, theoretical onset times, ray parameters and backazimuth values were calculated for each event in the reference list, using the standard radial symmetrical Earth model ak135 (Kennett et al. 1995); the travel times were corrected for the ellipticity of the Earth (Kennett and Gudmundsson, 1996). Then, the listings of automatically estimated f-k results (Pirli, 2005, Pirlis, 2006) achieved by the application of the EP algorithm (Fyen 1989) were searched for seismic onsets fitting the theoretical onset parameters of first P-type onsets from these events. Typical frequency ranges for the detection of teleseismic onsets are $0.8-3.0 \mathrm{~Hz}$ and $1.0-4.0 \mathrm{~Hz}$, while typical f-k time windows range from 0.5 to $2.5 \mathrm{~s}$. To associate an onset to a specific event from the reference list, the following selection criteria were applied: the onset time residuum should be between -5.0 and $+10.0 \mathrm{~s}$ in order to take into consideration the cases of strong crustal reflections interfering with emergent first onsets, while the total length of the slowness vector residuum should not be larger than $12.0 \mathrm{~s} /{ }^{\circ}$. Application of these criteria, resulted in 275 onsets being associated to events of the reference list, which amounts to $25.3 \%$ of the events declared as observable actually being observed by TRISAR. With this value, TRISAR is exhibiting comparable far regional and teleseismic detection capabilities to e.g., the single station KHC (Harjes et al., 1994), located in Central Europe, far from all oceanic noise sources. All events for which TRISAR observed a first P-type onset are depicted on the map of Figure 3, denoted by filled circles.

The obtained dataset of observed onsets, although covering a total time interval less than one year, allows for a preliminary assessment of TRISAR detectability within the regional and teleseismic distance range. The applied approach involves investigating the spatial distribution of observed seismicity, the temporal variation of the array detection capability, as well as the analysis of residuals. The results of these investigations will be discussed in detail in the following sections. 


\section{Characteristics of the Observed Far-regional and Teleseismic First P-type Onsets}

\subsection{Observed Seismic Phases}

The teleseismic TRISAR observations mostly correspond to direct $\mathrm{P}$ onsets (200 observations), while for distances larger than approximately $100^{\circ}$ the obtained onsets are PKP and Pdif phases. A detailed sorting of observed phases within the presented study is provided in Table 1. Hwang and Clayton (1991) studied a vast number of seismic stations worldwide regarding their contribution to the catalogues of the ISC from 1964 through 1986. Station ATH, located close to TRISAR, reported over the entire investigated time period of 22 years $4966 \mathrm{P}$ and $1202 \mathrm{PKP}$ observations, an average of about $225 \mathrm{P}$ and $55 \mathrm{PKP}$ observations per year. It seems that the automatic

Table 1 - Number of first P-type
onsets observed by TRISAR

\begin{tabular}{|l|l|}
\hline Phase name & Number \\
\hline Pn & 2 \\
\hline$P$ & 200 \\
\hline Pdif & 4 \\
\hline PKPab & 74 \\
\hline PKPdf & 22 \\
\hline
\end{tabular}
processing of the test array data gives approximately the same amount of teleseismic observations as the permanent stations in the area, in particular taking in account that the whole processed TRISAR dataset covers only about three quarter of a year.

\subsection{Geographic Distribution of the Observed Events}

Comparing the geographic distribution of the whole amount of events contained in the reference list with that of events observed by TRISAR (Fig. 3), a discrepancy in the detection capability is clearly visible between the hemispheres east and west of the array. Indeed, the number of observations is much larger in the eastern part than the one in the western part, both for the regional and teleseismic distance range. Some of this discrepancy can be explained by the fact that most of the seismicity in the Americas occurs at distances, for which TRISAR lays within or near the core shadow, indicated by the $100^{\circ}$ radius in Figure 3 .

Histograms describing the distribution of the number of observed and observable events, as well as the ratio of these two quantities with respect to the theoretical backazimuth (Fig. 4), are constructed in an attempt to obtain further insight into this uneven spatial distribution of the observed events. It is quite obvious that the largest amount of seismic activity for the time interval under investigation corresponds to backazimuth values between 60 and $120^{\circ}$; the main contributor is the activity in the Sumatra, Nicobar and Andaman Islands region following the December 26, 2004 devastating earthquake. The high detectability percentages observed for backazimuth ranges of 210 to $240^{\circ}$ and 330 to $360^{\circ}$ may be purely coincidental, as the actual number of occurring events is quite small. Apart from these two 'peaks', the general trend is that detectability levels deteriorate for increasing backazimuth values. Such an azimuthal distribution is confirmed by Hwang and Clayton (1991) also for other seismic stations in Greece (e.g. ATH, ITM, PLG, PTL, VLS). The limited data-set provides however no real insight into the reasons for low detectability levels in the Americas and Eastern Pacific, as clearly exhibited in Figure 3.

The observations are more straightforward regarding the distribution of the number of events with respect to their epicentral distance (Fig. 5). In general, within the regional - far regional distance range there is no great abundance of events, however detectability levels are quite satisfactory. Well above average $(25.3 \%)$ is also detected in the Sumatra, Nicobar and Andaman Islands region at around $70^{\circ}$ distance. Then, the detectability declines as distance increases, until the P-wave shadow-zone is reached at around $100^{\circ}$. The next characteristic peak is the PKP caustic effect around $145^{\circ}$. Thus, it becomes clear that TRISAR observations are consistent with major Earth structure effects. 


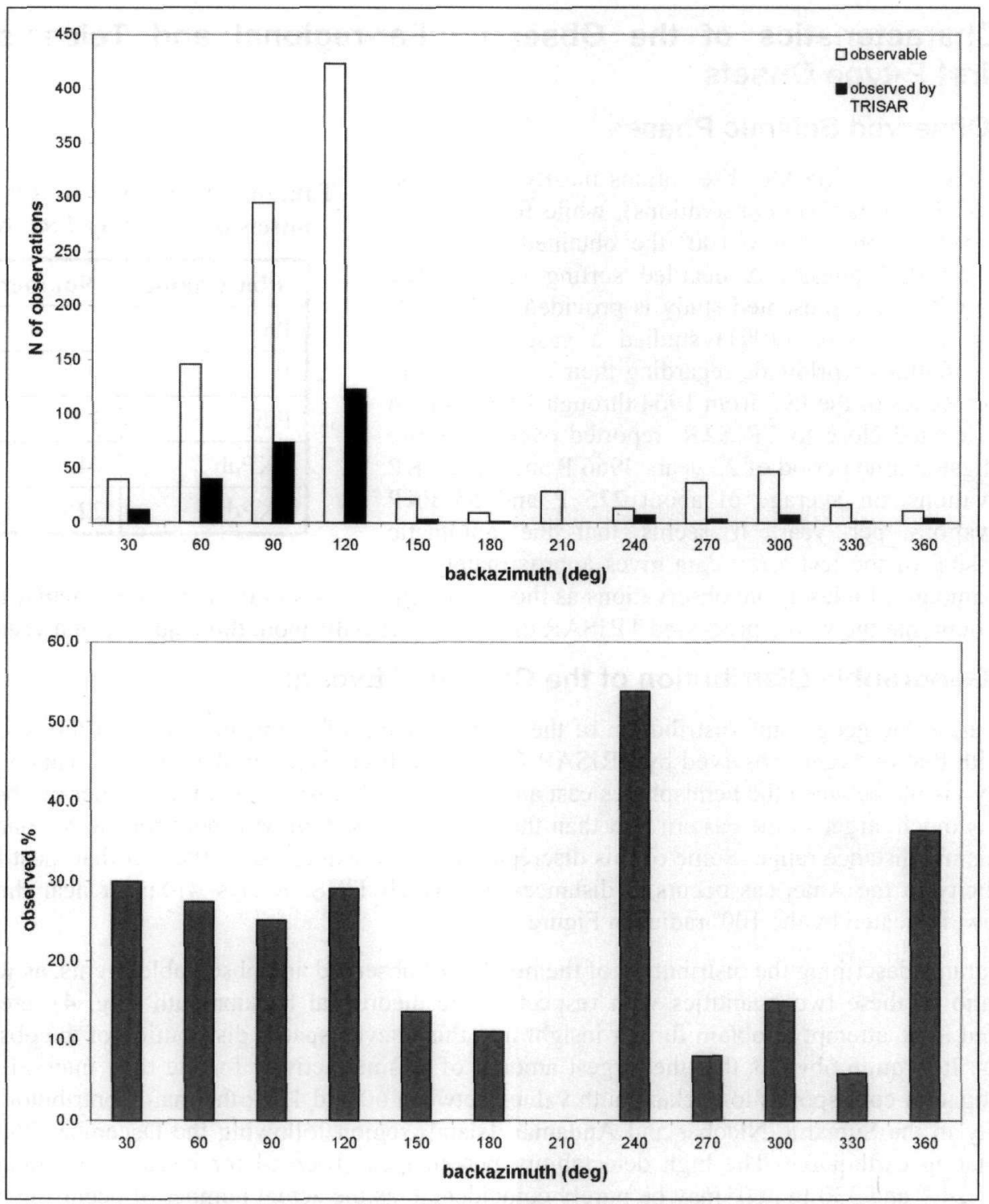

Figure 4 - Number of observable and observed seismic events against theoretical backazimuth with respect to TRISAR. Data are binned in $30^{\circ}$ intervals (top). Percentage of the actually observed events for corresponding bins (bottom)

\subsection{Travel-time and Backazimuth Residuals}

A histogram of the travel-time residual distribution for the observed onsets is presented in Figure 6. The distribution can be generally described as Gaussian. The residual mean value of $1.68 \mathrm{~s}$ can easily be explained as the effect of the known baseline shift between the applied model ak135 and the Jeffreys-Bullen model (Kennett et al. 1995) used at the data centres to locate the reference events. Hwang and Clayton (1991) also published P-type residuals for seismic stations. For stations ATH and ITM, operated by the National Observatory of Athens and located close to TRISAR, the observed mean P-phase travel-time residuals are close to zero with respect to the Jeffreys-Bullen tables (1940). Taking these points into consideration, the obtained time residual distribution for TRISAR observations verifies the validity of the performed onset associations and thereby the conclusions of this study. 


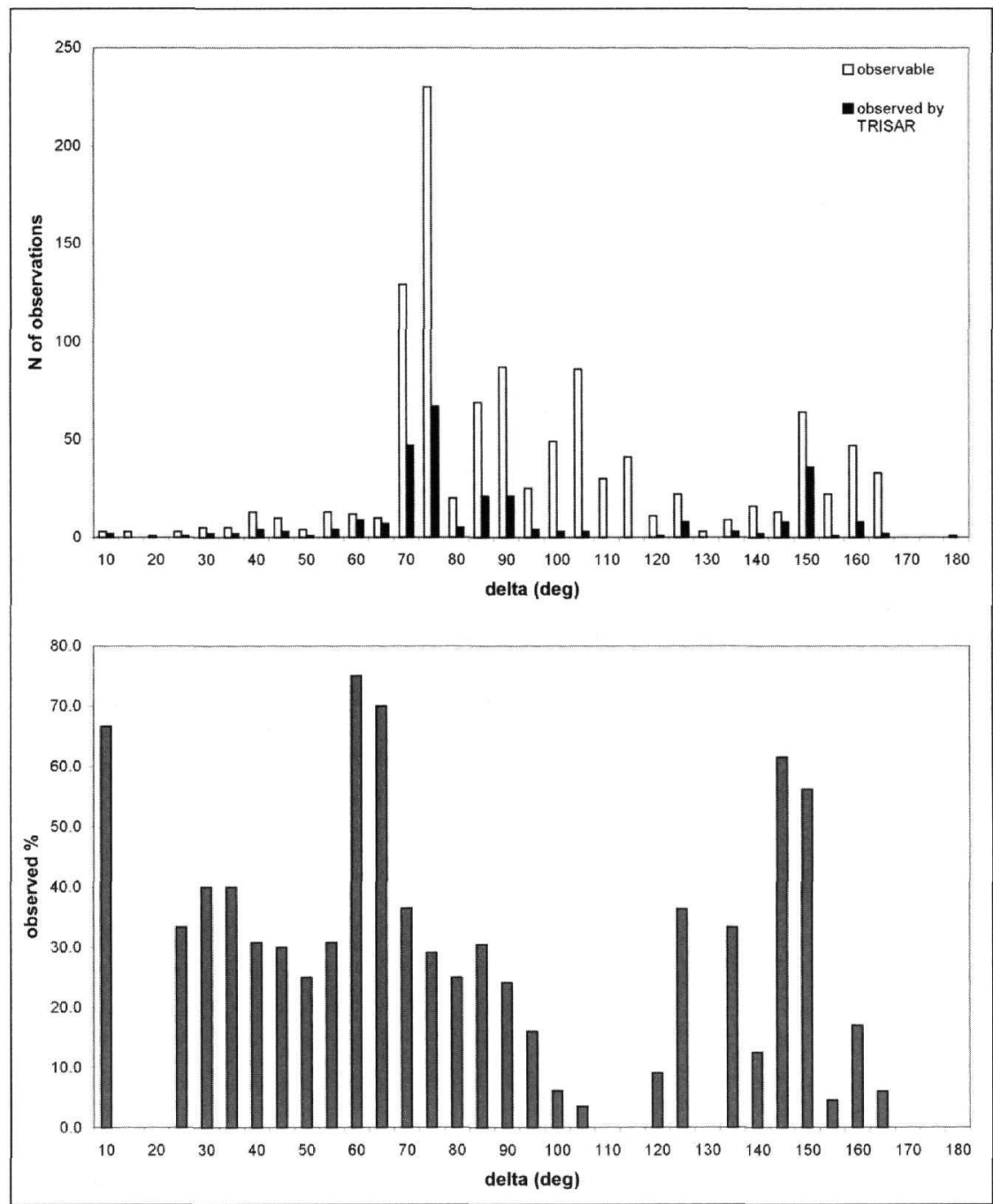

Figure 5 - Number of observable and observed seismic events against epicentral distance with respect to TRISAR. Data are binned in $5^{\circ}$ intervals (top). Percentage of the actually observed events for corresponding bins (bottom)

As already mentioned, most observations are distributed within the azimuthal range of 40 and $100^{\circ}$. Since observed onsets are scarce for backazimuth values larger than $210^{\circ}$, no clear trend can be obtained. However, the general impression derived from the backazimuth residual distribution between these two ranges differs significantly (Fig. 7). For backazimuth values larger than $210^{\circ}$, residuals are characterized almost entirely by positive values of lower mean level than for the range between 40 and $100^{\circ}$. Within this range, two main concentrations of events can be observed around 70 and $95^{\circ}$. Both of them however, as also true for the whole distribution, display significant scatter. This is expected, due to the limited resolution of the array. The concentration observed around $70^{\circ}$ corresponds exclusively to negative residuals whereas, for backazimuth values around $95^{\circ}$ there is also a relatively small number of events with positive residuals.

A clearer image of the backazimuth residual distribution can be expected for a more extended dataset than the one used in this study. In particular, it would be interesting to have more events available for backazimuth values larger than $210^{\circ}$, as well as an adequate amount of data from southerly directions, where no information is now available. 


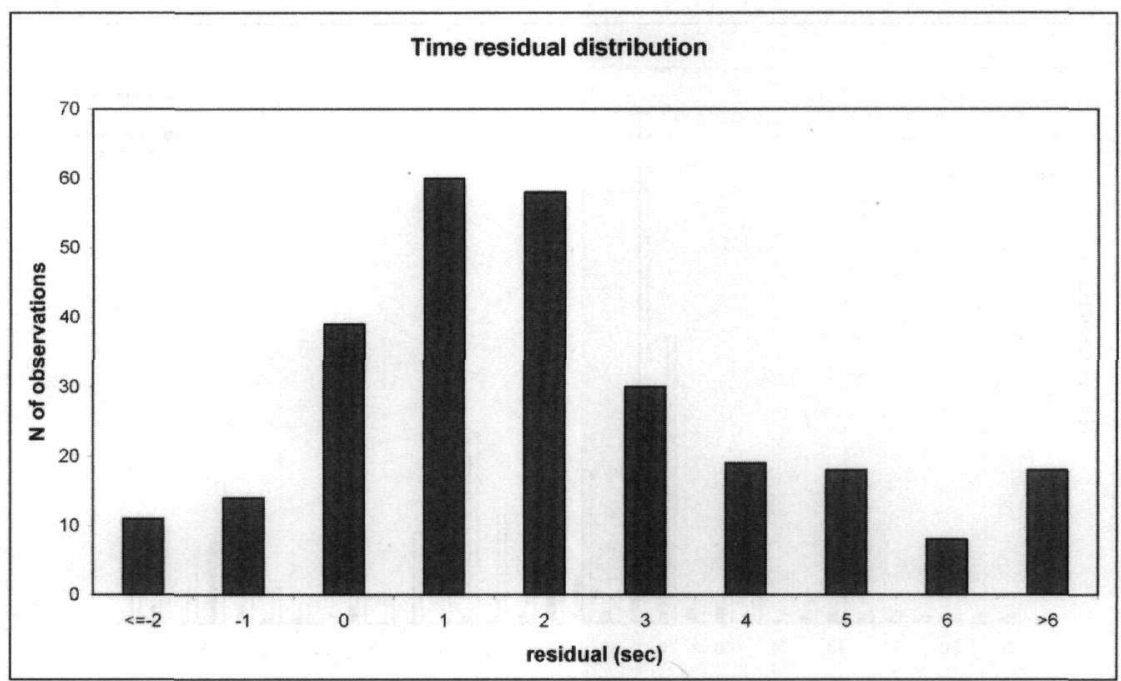

Figure 6 - Travel-time residual distribution for the 1089 events observed by TRISAR. All residuals are calculated as observed minus theoretical onset times with respect to model ak135 (Kennett et al. 1995)

No particular reference is made in this study regarding ray parameter residuals, as the significant scatter due to TRISAR small aperture prohibits the extraction of any clear conclusions. Indeed, as derived from research involving the calculation of TRISAR mislocation vectors for local and regional distances, the scatter of the backazimuth values appears to be significantly smaller than that of ray parameter (Pirli et al. 2007).

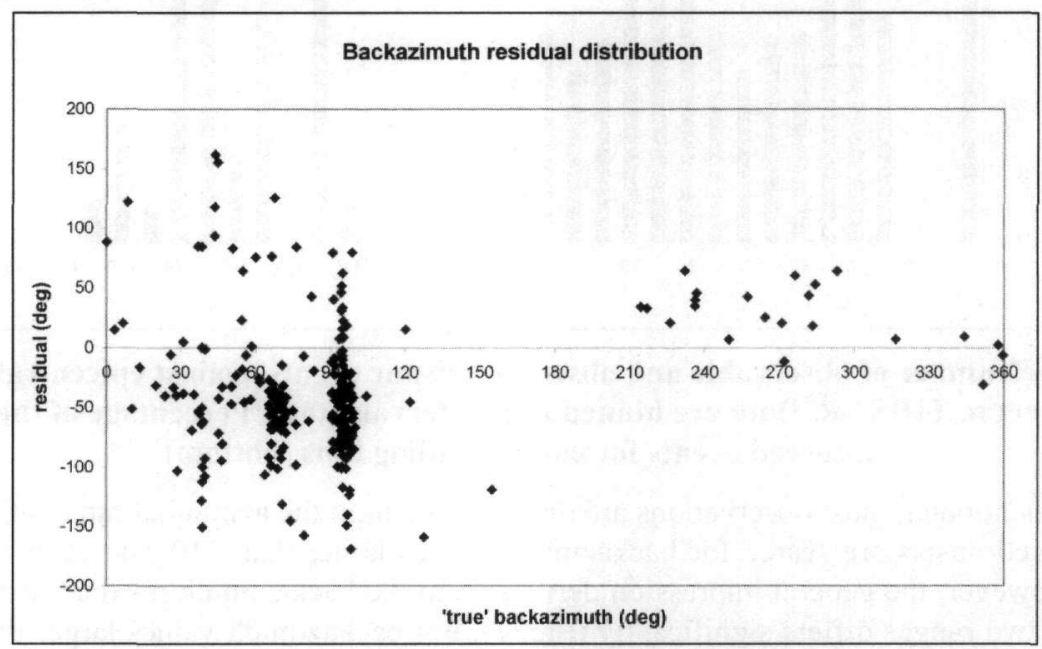

Figure 7 - Backazimuth residual distribution against 'true' backazimuth for the 1089 observed events

\subsection{Detection Capability Variation with Time}

The detection capability of each seismic station varies with time mainly due to variations in the background noise level. The main contributors to the time dependence of noise are human activity and seasonal weather changes (e.g. Harjes et al. 1994). The human factor on the detection capability is usually depending on the time of day and the distribution between working days and holidays. The currently available TRISAR dataset is too small to investigate these factors in all detail. 


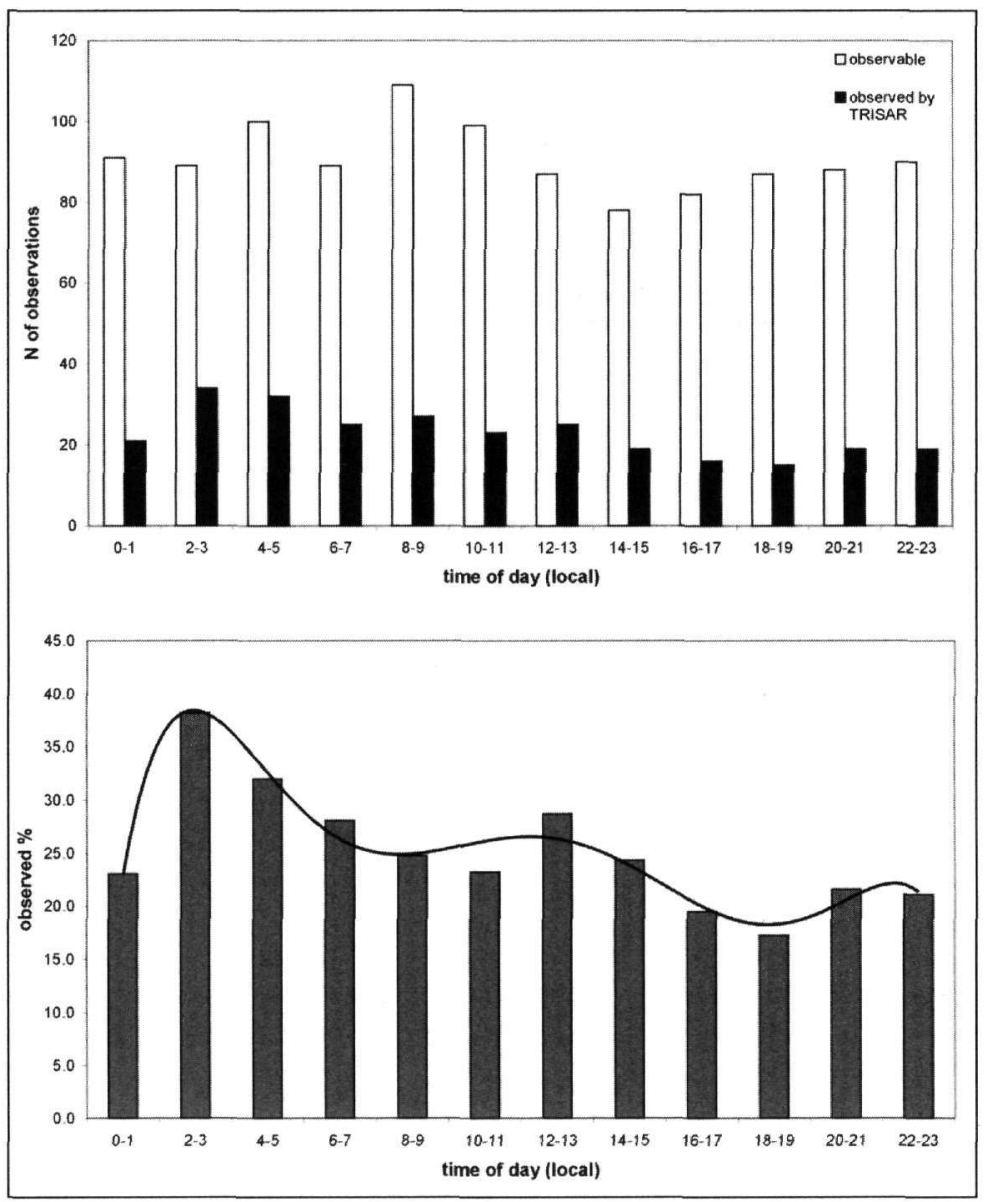

Figure 8 - Number of observable and observed seismic events against time of day for TRISAR. Data are binned in 2 hour intervals (top). Percentage of the actually observed events for corresponding bins (bottom)

However, histograms could be constructed (Fig. 8) exhibiting the distribution of the number of observed events and the ratio observed/observable events with respect to local time of day (binned in 2 hour intervals), in order to investigate the effect of local anthropogenic noise on the array detection capability. Consistently to human activity rush hour and hiatus intervals, the percentage of observed events is highest during the first hours of day, decreasing significantly during the morning activity and reaching its lowest level between 16:00 and 19:00 local time. Such an interpretation is justified taking into account the location of the array in a military camp and its proximity to the town of Tripoli, as well as smaller villages within the same radius. This general trend is also described by the best fitting 6th order polynomial curve.

\section{Conclusions}

Despite its limited resolution, that does not permit the location of regional and teleseismic events, preliminary investigation indicates that the TRISAR array is characterised by detectability for the corresponding distance range comparable to that of single stations located in Central Europe. It should be taken into consideration that a 4-element array as TRISAR can theoretically increase the signal-to-noise ratio merely by a factor of 2 . Therefore, it is expected that for teleseismic distances TRISAR is performing similarly to a single station. In accordance to this, the total number of teleseismic P-type onsets automatically detected by TRISAR and used in this study is also in the 
same order as the average number of onsets per year reported by permanent single stations in Greece, as published by Hwang and Clayton (1991) for a 22 year interval.

The geographic distribution of observed onsets is fully consistent with major Earth structure features and shows no deviation from the general behaviour within this context of other seismic stations situated in Greece.

TRISAR teleseismic detection capability clearly exhibits the effect of human activity generated noise, as an obvious variation is observed with local time of day. Such a feature was expected, as TRISAR is located in the immediate vicinity of significant sources of anthropogenic noise (military unit, the town of Tripoli, highway etc.). It is deemed important however, that even under these conditions, satisfactory detectability levels are achieved. Any further investigation for weekly or seasonal variations in detection capability was impossible, as the available dataset covers a rather short time interval. A more elaborate study can be pursued in the future with a suitable dataset.

The limited data availability does also not allow for solid conclusions regarding backazimuth residual distribution. Obtained residual distributions are quite obscure due to the significant scatter that is expected for an array of such small aperture.

Further investigation is thereby recommended with the use of a much more extended dataset, as there are strong indications that such a small-aperture array may prove to be a useful tool for monitoring worldwide seismicity.

\section{Acknowledgments}

This manuscript has been improved by taking in account comments made by Keith D. Koper and an anonymous reviewer. Maps included in this paper were created using the GMT software package (Wessel and Smith 1991, 1998).

\section{References}

Alexopoulos, J., 1998. A contribution to the investigation of the hydrogeological regime of the Tripoli plateau, using geophysical methods, $P h D$ Thesis, University of Athens, Athens, 275 pp. (in Greek)

Fyen, J., 1987. Improvements and modifications, NORSAR Sci. Rep. 2-86/87, NORSAR, Kjeller, Norway.

Fyen, J., 1989. Event Processor program package, NORSAR Sci. Rep. 2-88/89, NORSAR, Kjeller, Norway.

Hwang, L.J., and Clayton, R.W., 1991. A station catalog of ISC arrivals: seismic station histories and station residuals, USGS Open-File Rep. 91-295, 28pp.

Harjes, H.-P., Jost, M., and Schweitzer, J., 1994. Preliminary calibration of candidate alpha stations in the GSETT-3 network, Annali Geofis., 37, 383-396.

ISC, 2006. International Seismological Centre On-line Bulletin, http://www.isc.ac.uk/Bull, Intern. Seis. Cent., Thatcham, United Kingdom.

Jeffreys, H., and Bullen, K.E., 1940. Seismological Tables, British Association Seismological Committee, London, United Kingdom, 50pp.

Kennett, B.L.N., Engdahl, E.R., and Buland, R., 1995. Constraints on seismic velocities in the Earth from traveltimes, Geophys. J. Int., 122, 108-124.

Kennett, B.L.N., and Gudmundsson, O., 1996. Ellipticity corrections for seismic phases, Geophys. J. Int., 127, 40-48. 
Kværna, T., and Doornbos, D.J., 1986. An integrated approach to slowness analysis with arrays and three-component stations, NORSAR Sci. Rep. 2-85/86, NORSAR, Kjeller, Norway, 6069.

Kværna, T., and Ringdal, F., 1986. Stability of various f-k estimation techniques, NORSAR Sci. Rep. 1-86/87, NORSAR, Kjeller, Norway, 29-40.

Mykkeltveit, S., and Bungum, H., 1984. Processing of regional seismic events using data from small-aperture arrays, Bull. Seismol. Soc. Am., 74, 2313-2333.

Pirli, M., 2005. A contribution to earthquake location in Greece with the use of seismic arrays, $P h D$ Thesis, University of Athens, Athens, $256 \mathrm{pp}$. (in Greek)

Pirli, M., Voulgaris, N., Alexopoulos, J., and Makropoulos, K., 2004. Installation and preliminary results from a small aperture seismic array in Tripoli, Greece, Bull. Geol. Soc. Greece, XXXVI, 1499-1508.

Pirli, M., Pirlis, E., and Voulgaris, N., 2007. Mislocation vectors for the Tripoli Seismic Array, Greece, and structural effect implications from backazimuth and slowness residual analysis, Bull. Geol. Soc. Greece, this volume.

Pirlis, E., 2006. Evaluation of the automatic data processing algorithm and investigation of calibration possibilities for the Tripoli Seismic Array, MSc Thesis, University of Athens, Athens, 197pp. (in Greek)

Schweitzer, J., Fyen, J., Mykkeltveit, S., and Kværna, T., 2002. Chapter 9: Seismic Arrays. In P. Bormann (ed), IASPEI New Manual of Seismological Observatory Practice (NMSOP), vol. 1, 52pp., GeoForschungsZentrum, Potsdam.

Wessel. P., and Smith, W.H.F., 1991. Free software helps map and display data, EOS Trans. Am. Geophys. Union, 72, 441, 445-446.

Wessel, P., and Smith, W.H.F., 1998. New, improved version of Generic Mapping Tools released, EOS Trans. Am. Geophys.Union, 79, 579. 